- COMMENTARY

Volume 9 Issue 42017

DOI: 10.21315/eimj2017.9.4.7

ARTICLE INFO

Submitted: 21-7-2017

Accepted: 22-9-2017

Online: 29-12-2017

\title{
Malaysian Medical License Examination (MMLE): Is This a Way Froward?
}

\author{
Amit Bhardwaj', Kavitha Nagandla², Sadoon Ibrahim ${ }^{3}$ \\ ${ }^{1}$ Department of Orthopaedics, Newcastle University Medicine \\ Malaysia, fohor, MALAYSIA \\ ${ }^{2}$ Department of Obstetrics and Gynaecology, International Medical \\ University, Seremban, MALAYSIA \\ ${ }^{3}$ Department of Orthopaedics, Hospital Sultanah Ismail, fohor Bahru, \\ MALAYSIA
}

To cite this article: Bhardwaj A, Nagandla K, Ibrahim S. Malaysian Medical License Examination (MMLE): is this a way froward? Education in Medicine Journal. 2017;9(4):63-67. https://doi.org/ 10.21315/eimj2017.9.4.7

To link to this article: https://doi.org/10.21315/eimj2017.9.4.7

\begin{abstract}
Medical education in Malaysia is facing challenges related to the increasing number of local private and foreign medical universities. The key issue is whether the system is producing doctors who have adequate competencies for fundamental patient-centred care. The Malaysian Medical Licensing Examination (MMLE) was proposed by the Ministry of Health $(\mathrm{MOH})$ as a common licensing examination for which all graduates must sit prior to obtaining registration to practice. Currently, this exam is only taken by Malaysian students graduating from foreign medical colleges. However, the local Malaysian universities, both public and private, have different curricula for preparing undergraduates for future housemanships. The question is whether the educational programs of these universities are robust enough in delivering curricula that produce safe and competent doctors. Moving forward, it must be determined whether there is a need for extending the Malaysian Medical Licensing Examination (MMLE) to all graduates of both local and foreign medical universities, thereby creating a marker of excellence by which to measure Malaysian education and practice.
\end{abstract}

Keywords: Malaysian Medical Licensing Exam, Competency, Curriculum

Kavitha Nagandla, Senior Lecturer, Department of Obstetrics and Gynaecology, International Medical University, Jalan Rasah, 70200 Seremban, Negeri Sembilan, Malaysia | Email: kavitha.nagandla@gmail.com

\section{INTRODUCTION}

Medical education in Malaysia is currently facing challenges in trying to address whether the system produces doctors with adequate competencies for fundamental patient-centred care (1). Currently there is no process to evaluate whether the existing educational programs are robust enough in delivering curricula that produce safe and competent doctors. The Ministry of Health
$(\mathrm{MOH})$ proposed the Malaysian Medical Licensing Examination (MMLE) as a common licensing examination for which all graduates must sit prior to obtaining registration to practice. Currently, this exam is only taken by Malaysian students graduating from foreign medical colleges. All the local Malaysian universities, both public and private, have different curricula for preparing undergraduates for future housemanships. Considering this issue, 
a mandated medical licensing exam for all graduates in Malaysia could help in monitoring their knowledge and skills. Is it time for Malaysia to consider a mandatory licensing exam for all medical graduates, including those of local colleges?

\section{THE DRIVERS FOR MALAYSIAN MEDICAL LICENSING EXAM}

\section{Historical Context}

Data from the US and Canada demonstrate that exit exams can be valid and reliable, showing adequate correlation between a graduate's clinical skills and future performance (2). There is evidence suggesting that students who perform better in licensing exams practice better patient care $(3,4)$. However, it is concerning that findings from reputable universities have failed to establish a direct link between national licensing examinations and improved patient outcomes $(5,6)$.

\section{Political Context}

Globalisation in Malaysia has resulted in an increased demand for doctors, and this demand has been fulfilled by private medical schools. The accreditation of these medical schools is conducted by the National Accreditation Board and the Malaysian Medical Council. Despite an accreditation system, measurements have largely focused on processes rather than outcomes $(7,8)$. Therefore, the compulsion is for a national medical licensing examination that can serve to standardise the competencies expected. This would perhaps be perceived as a socio-cultural change driven by patient safety. On the other hand, how will an exam that exposes the lacunae in medical schools affect the power of the colleges and will it conflict with their vested interest in retaining autonomy over their businesses? Furthermore, will the licensing examination be considered valid in all the Association of Southeast Asian Nations (ASEAN) countries and will it support the ASEAN economic community (AEC) initiative, for which the practice of health professionals providing cross-border health services is considered crucial (9)? The General Medical Council (GMC) has announced that completion of the Medical Licensing Assessment (MLA) is mandatory for all graduates, irrespective of where they studied for their basic medical degree. The aim is to set a common threshold for entry into the GMC register by 2020 . With this precedent, and with the adoption of UK protocols into Malaysian health care policy guidelines, the authors opine that the Malaysian Medical Council is leading medical education in Malaysia into the future (10).

\section{Educational Context}

The majority of medical schools in Malaysia have adopted an integrated approach that uses organ systems-based modules for delivery of the curricula. Richard Hays has illustrated the differences and the relationship between potential, planned, delivered, assessed and hidden curricula (11). The planned, delivered and assessed curricula must match, as a mismatch might surface an undesirable curriculum - the hidden curriculum - that would hinder the achievement of the planned educational objectives, a concept referred to as a curriculum war (Figure 1). It is expected that a national licensing exam will make explicit the assessed curriculum; this will help to determine whether medical schools are delivering the curriculum as planned. However, if a licensing exam is imposed, would it deter enthusiasm for bringing new and innovative teaching and learning strategies into the curriculum? (12). Moreover, a licensing exam would mandate the need for coordinated planning by key stakeholders, including the Malaysian Medical Council and medical school assessment experts, in order to develop a unified, qualifying final exam that integrates the MMLE and avoids redundancy between assessments. 


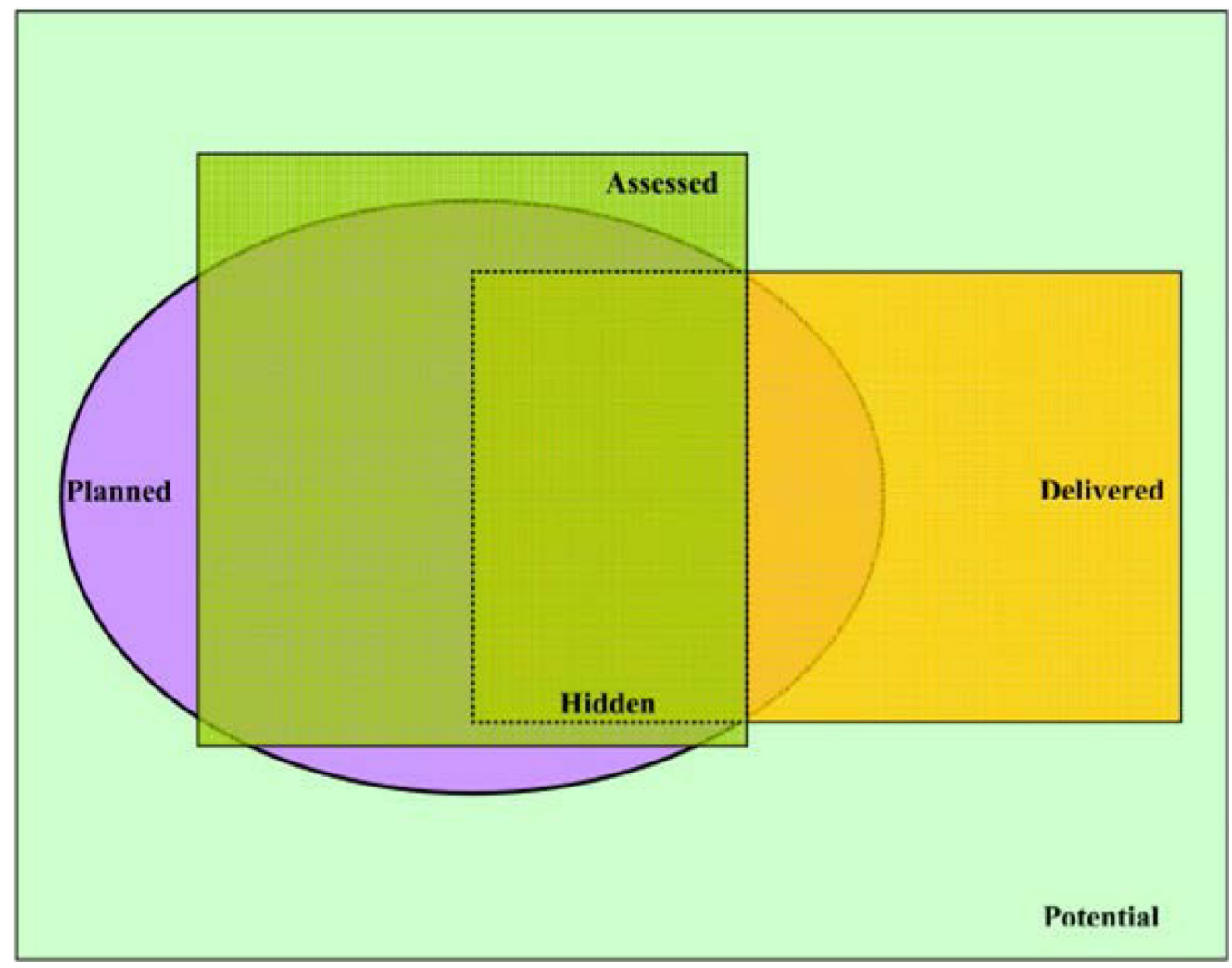

Figure 1: Curriculum war, adapted from Hays R (11).

\section{Theoretical Context}

The theory underpinning the national licensing exam is that national examinations ensure that doctors have achieved minimum standards of competency before beginning to practice. The priority is the construction of a clinically relevant blueprint that reflects the actual clinical tasks and problems that the candidates will be required to competently address in accordance with national standards. According to Swanson et al. (13) and Van der Vleuten et al. (14), a wide sampling across clinical issues is required if an adequate level of content validity and reliability is to be achieved. The solution is perhaps to combine the objective structured clinical examination (OSCE) with multiple-choice questions for efficient sampling. However, whatever assessment format is used, how precisely will one be able to determine whether every graduate of every medical school is good and that patient safety is assured? Furthermore, given that the literature on litigation focuses more on 'soft skills' than on knowledge, will a licensing exam that is largely knowledge-based, or even OSCEstyle, address this competency adequately (14)? There are discouraging reports on the continued use of United States Medical Licensing Examination (USMLE) Step 1 and Step 2 scores for postgraduate medical residency selection decisions (4). In a recent nationwide study on the Malaysian house officers training ( $\mathrm{n}=407$ ) needs in core competency procedures in Obstetrics \& Gynaecology, concerns were identified that graduates from different medical schools exhibited noticeably variable procedural skills and knowledge application upon entering their housemanships. This study has implications for the feedback given to medical schools regarding the adequacy of graduate training in preparation for housemanships. This finding highlights the need for a unifying assessment by MMLE or for the integration of MMLE into medical schools' final exams $(15,16)$. 


\section{Socioeconomic Context}

Are the advantages of the examination sufficient to justify its expense? Evidence of the exam's benefits is far from clear-cut (6). Is the country ready to measure and manage the outcomes of such an exam? The exam will further increase the financial burden on recent graduates. Other challenges include how to write good questions and how to obtain agreement among different medical schools on the standard exam. The process of planning, constructing the questions and analysing the exam's results is arduous. There is a significant need for space to accommodate the test, money to fund it, and committed faculty to initiate and maintain the process.

\section{CONCLUSIONS}

There is no doubt that an increase in work force demand is fulfilled by increasing the number of private medical schools. However, there should be requirements for the planning, consolidation of resources, infrastructure creation and development of a quality assurance system with regards to the standardisation of medical competencies so that qualified doctors are ensured to have achieved the desired outcomes. If this need is addressed, the way forward is a medical licensing exam that will advance the health care system and that can perhaps make Malaysia a nodal centre for medical education in South East Asia. Whether MMLE remains a standalone exam or is integrated into final exams, as planned by GMC mandates, stakeholders should undertake analysis to identify the best possible strategy for the implementation of the licensing exam.

\section{CONFLICTS OF INTEREST}

The above views of the Malaysian Medical Licensing exam are solely those of the author and are not the views of the Newcastle University, Malaysia.

\section{REFERENCES}

1. C21 Editorial. Common licensing exam for medical grads. 2014 May 12. Available from: http://mymedicnews.com/industrynews/2373-common-licensing-exam-formedical-grads/May\%2012\%202014\%20 New\%20straits

2. Van Zanten M, Boulet JR, McKinley DW. Correlates of performance of the ECFMG clinical skills assessment: influences of candidate characteristics on performance. Acad Med. 2003;78(Suppl):S72-4. https:// doi.org/10.1097/00001888-20031000100023.

3. Wakeford R, Foulkes J, McManus C, Southgate L. MRCGP pass rate by medical school and region of postgraduate training. Royal College of General Practitioners. BMJ. 1993;307:542-3. https://doi.org/10.1136/ bmj.307.6903.542-a.

4. McGaghie WC, Cohen ER, Wayne DB. Are United States medical licensing exam step 1 and 2 scores valid measures for postgraduate medical residency selection decisions? Acad Med. 2011;86(1):48-52. https://doi.org/10. 1097/ACM.0b013e3181ffacdb.

5. Swanson DB, Roberts TE. Trends in national licensing examinations in medicine. Med Educ. 2016;50(1):101-14. https://doi.org/ $10.1111 /$ medu. 12810 .

6. Archer J, Lynn N, Roberts M, Coombes L, Gale T, de Regand Bere S. A systematic review on the impact of licensing examinations for doctors in countries comparable to the UK. Final report to the GMC. Collaboration for the Advancement of Medical Education Research. Plymouth, England: Plymouth University Peninsula; 2015 May 29.

7. Malaysian Medical Council. 2007. National Accreditation Board and Malaysian and Medical Council. [cited 2017 September]. Available from: http:/www.mmc.moh.gov.my 
8. Lim VKE. Medical education in Malaysia. Med Teach. 2008;30(2):119-23. https://doi. org/10.1080/01421590801942102.

9. Kanithasen P, Jivakanont V, Boonnuch C. AEC 2015: ambitions, expectations and challenges ASEAN's path towards greater economic and financial integration. Bangkok: Bank of Thailand; 2011.

10. General Medical Council. n.d. Medical Licensing Assessment. http://www.gmc-uk. org/education/29000.asp

11. Hays R. What can be learnt in clinical settings? In: Hays $\mathrm{R}$, editors. Teaching and learning in clinical settings. Abingdon: Radcliffe; 2006. p. 109-23.

12. Stenhouse L, editor. Curriculum research and development in action. London: Heinemann Educational Publishers; 1980.

13. Swanson DB, Norcini JJ, Grosso LJ. Assessment of clinical competence: written and computer-based simulations. Assess Eval Higher Educ. 1987;12:220-46. https://doi. org/10.1080/0260293870120307.
14. Van der Vleuten CPM, Norman G, De Graaff E. Pitfalls in the pursuit of objectivity: issues of reliability. Med Educ. 1991;25:110-18. https://doi.org/10. 1111/j.1365-2923.1991.tb00036.x.

15. Reader TW, Gillespie A, Roberts J. Patient complaints in healthcare systems: a systematic review and coding taxonomy. BMJ Qual Saf. 2014;23:678-89. https://doi. org/10.1136/bmjqs-2013-002437.

16. Idris N, Nagandla K, Sivalingam N, Hari Krishnan KK, Ravichandran J. The training needs of Malaysian house-officers on core obstetric and gynaecological competencies. Oral presentation at International Medical Education Conference (IMEC); 2017 April 7-9. 